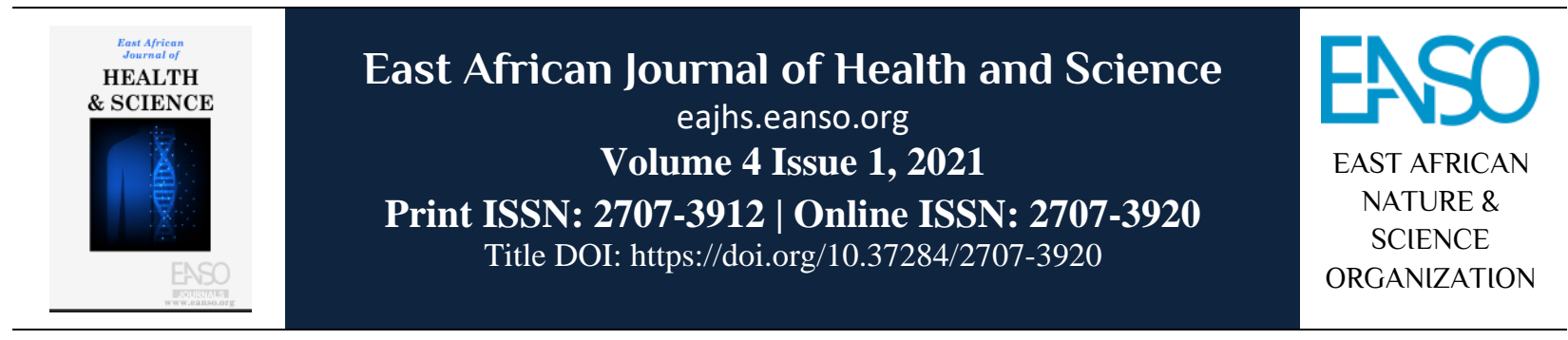

Original Article

\title{
The Demographics Behind the Courage to Tell for Survivors: Child Sexual Abuse Experiences in Kenya.
}

\author{
Wamuyu Eunice Menja ${ }^{*}$, Dr. Lucy Kathuri-Ogola, $P h D^{1}$, Dr. Joan Kabaria Muriithi, PhD ${ }^{1}$ \& \\ Dr. Taren Swindle, $P h D^{1}$ \\ ${ }^{1}$ Population Reproductive Health and Community Resource Management Department, Kenyatta University, P. O. Box 43844- \\ 00100, Nairobi, Kenya. \\ ${ }^{1}$ Family and Preventative Medicine Department, the University of Arkansas for Medical Sciences, Little Rock. \\ *Author for correspondence email: emenja@gmail.com.
}

Article DOI: https://doi.org/10.37284/eajhs.4.1.475

\section{Date Published: ABSTRACT}

16 November 2021 Child Sexual Abuse (CSA) is both a global and national social issue, as well as an epidemic in various societies. Non-disclosure of CSA only worsens

Keywords: and extends survivors' suffering, and CSA's long-term effects can be devastating. Several studies have been done in the field of CSA and its

Child, health implications but rarely have previous studies addressed child sexual Sexual Abuse, abuse disclosure (CSAD). The current study aimed at examining child Disclosure, Survivor, Perpetrator. factors of CSAD at Thika Level 5 Hospital (TL5H) in Kiambu County, Kenya. The study is a case study using a phenomenology approach where the primary data was collected from the sexual abuse survivors and caregivers using a mixed-method analysis. Interviews were conducted with 30 CSA survivors, 25 girls, and 5 boys: 5-17 years. The study utilised the convergent QUAL (investigative open-ended questions and storytelling) design with a Quan component (structured survey) to identify CSA survivors' experiences while receiving medical treatment and therapeutic intervention at TL5H. Descriptive and thematic approaches were applied to analyse qualitative data that revealed survivors' lived experiences with CSA. Informed by Bronfenbrenner's Socio-Ecological Model (SEM), saliency analysis was applied to code the recurring and important themes from the data in order to identify which child factors. Survivors gave detailed accounts of types of threats and manipulation applied by perpetrators to stop them from disclosing abuse. Survivors said disclosing or not disclosing helped them cope with abuse trauma. Quantitative results revealed that $58 \%$ of the survivors who completed the disclosure process

61 This work is licensed under a Creative Commons Attribution 4.0 International License. 
aged between 9-13 years, $83.3 \%$ were female, and $70 \%$ had achieved a lower level of education.

\section{APA CITATION}

Menja, W. E., Kathuri-Ogola, L., Muriithi, J. K. \& Swindle, T. (2021). The Demographics Behind the Courage to Tell for Survivors: Child Sexual Abuse Experiences in Kenya. East African Journal of Health and Science, 4(1), 61-72. https://doi.org/10.37284/eajhs.4.1.475.

\section{CHICAGO CITATION}

Menja, Wamuyu Eunice, Lucy Kathuri-Ogola, Joan Kabaria Muriithi, \& Taren Swindle. 2021. "The Demographics Behind the Courage to Tell for Survivors: Child Sexual Abuse Experiences in Kenya.". East African Journal of Health and Science 4 (1), 61-72. https://doi.org/10.37284/eajhs.4.1.475.

\section{HARVARD CITATION}

Menja, M. W., Kathuri-Ogola, L., Muriithi, J. K. \& Swindle, T. (2021) "The Demographics Behind the Courage to Tell for Survivors: Child Sexual Abuse Experiences in Kenya.", East African Journal of Health and Science, 4(1), pp. 61-72. doi: 10.37284/eajhs.4.1.475.

\section{IEEE CITATION}

M. W. Menja, L. Kathuri-Ogola, J. K. Muriithi, \& T. Swindle, "The Demographics Behind the Courage to Tell for Survivors: Child Sexual Abuse Experiences in Kenya.”, EAJHS, vol. 4, no. 1, pp. 61-72, Nov. 2021.

\section{MLA CITATION}

Menja, Wamuyu Eunice, Lucy Kathuri-Ogola, Joan Kabaria Muriithi, \& Taren Swindle. "The Demographics Behind the Courage to Tell for Survivors: Child Sexual Abuse Experiences in Kenya.”. East African Journal of Health and Science, Vol. 4, no. 1, Nov. 2021, pp. 61-72, doi:10.37284/eajhs.4.1.475.

\section{INTRODUCTION}

Child Sexual Abuse (CSA) is categorised as a form of child abuse and is one of the most confusing and perplexing problems facing many societies in the world, including Kenya. CSA is defined as the involvement of a child in sexual activity that he or she does not fully comprehend, is unable to give informed consent to, or for which the child is not developmentally prepared and cannot give consent, or that violates the laws or social taboos of society (World Health Organization, 2003). Any sexual act with a child, performed by an adult or an older child, who cannot give consent by age, disability, or because of the fear of harm by the perpetrator (Karakurt \& Silver, 2014) is categorised as CSA. The impact of CSA on children is documented, both globally and nationally. However, research shows a high percentage of children and youth $(60-80 \%)$ delayed disclosure until adulthood. The survivors endure un-intervened pain and suffering when disclosure is delayed (Vizard, 2013).

Wihbey (2011) writes Center for Disease Control (CDC) established that globally, $11 \%$ and $4 \%$ of high school girls and boys respectively had reported CSA. However, cases of under-reporting were common due to the stigma associated with Child
Sexual Abuse. Pereda et al. (2009) analysed 65 research studies in 22 countries and found $7.9 \%$ of males and $19.7 \%$ of females' worldwide experienced CSA before they turned eighteen. In North America, the prevalence of CSA was 7.5\% and $25.3 \%$ for males and females, respectively, while Europe had a prevalence of $9.2 \%$. CSA prevalence for Asia and Africa stood at $23.9 \%$ and $34 \%$, meaning Africa had the highest incidence of CSA. Specific to various African countries, the prevalence rate for South Africa was highest at $61 \%$ for males and $43.7 \%$ for females; Tanzania had a $25 \%$ and $31.0 \%$ prevalence rate among males and females, respectively (Pereda et al., 2009).

Kenya's reported CSA incidence was slightly lower at $22 \%$ and $17 \%$ for males and females, respectively (Sumner et al., 2015). A report by UNICEF (2014) indicates that more than $10 \%$ of Kenyan females experience CSA before 19 years. The same report indicated at least $37 \%$ of those victims were abused before they reached 10 years. UNICEF noted that $24 \%$ of the male victims experienced their first CSA before they reached 14 years. Across the globe, CSA is a predominant problem and needs to be addressed to support survivors' recovery. 
CSA is both a Social Justice and Public Health issue that continues to affect many societies around the world (Spröber et al., 2014; Vizard, 2013). There is scarce data on disclosure both globally and in Kenya. In Kenya, CSAD is expected to be minimal due to the level of silence and secrecy that surrounds the vice (Vizard, 2013). Due to the high levels of secrecy, silence, and stigmatisation, its impact has not been adequately analysed. Fear of CSA survivors being stigmatised and the encountered feelings of shame contribute to less disclosure, and few studies on CSA (Jackson et al., 2015; Karakurt $\&$ Silver, 2014).

A study by Ulibarri et al. (2015) found CSA to be associated with both depression and Post-Traumatic Stress Disorder (PTSD). CSA causes suffering for the survivors, families, and communities, while lack of CSAD or delayed CSAD is associated with PTSD and other mental health problems (Cantón-Cortés et al., 2012; Easton, 2013; Karakurt \& Silver, 2014; Vizard, 2013). The survivors of CSA are known to develop a sense of hopelessness, shame, and fear, especially if the abuse continues (Easton, 2013).

Child Sexual Abuse cannot be alleviated without disclosure, making it necessary to establish survivor factors that promote disclosure as a pathway to increase community resources (e.g., mental health and social services) for survivors. Research continues to motivate medical professionals and service providers to address mental health issues and post-traumatic disorder (PTSD) related to CSA (Ulibarri et al., 2015). Sufficient mental health and social services, both formal and informal, encourage survivors to seek support to minimise the effects of trauma during the CSAD process (Vizard, 2103). If CSA survivors feel safe in the hands of supportive confidants and trained staff, they are more likely to give full disclosure (Jackson et al., 2015; Vizard, 2013). Awareness of resources makes survivors safe throughout recovery.

\section{Research Questions}

Since Child Sexual Abuse Disclosure (CSAD) is a phenomenon that has barely been studied, both globally and locally, the researcher decided to engage in a more intensive data collection without having to be constrained by hypothesis testing. With a goal to address the gaps and broaden the literature on CSAD, the following objectives were established.

Do older children disclose sexual abuse more than younger children?

Do girls disclose sexual abuse more than boys?

Does a child's educational level help in the disclosure of sexual abuse?

Does a child's health support determine their level of sexual abuse disclosure?

\section{LITERATURE REVIEW}

\section{Child Characteristics and Child Sexual Abuse Disclosure}

Often, the survivor of CSA is the only witness of the sexual crime. This makes it necessary to study child characteristics that determine disclosure since information told by the survivor is a major piece of evidence in a sexual abuse case (Townsend, 2016). Child characteristics (e.g., gender, education level, age) encompass both the biological and personality developmental factors that may be related to the child's willingness to disclose.

Leclerc and Wortley (2015) studied the predictors of CSAD and concluded disclosure was positively related to survivors' age. The study indicated that survivors from non-dysfunctional families had higher disclosure. However, disclosure increased if the child and perpetrator stopped living together after the abuse. This may be explained by findings from other studies (Easton, 2013; Jackson et al., 2015) which indicated that CSA survivors fail to disclose because they are afraid of breaking families.

The child's social skills such as the ability to express their feelings with others facilitate disclosure. Consistent with other studies (Easton, 2013), a similar study carried out in Tanzania by Kisanga et al. (2011) observed that delayed or no disclosure was associated with stigma and shame. Since the survivors viewed CSA as shameful, they feared that disclosure would make them alienated from society. In line with this study, other researchers (Jackson et al., 2015) of CSA issues established that most of the CSA survivors were not 
willing to disclose because they felt socially powerless. The participants said things like, they either felt "embarrassed", "unworthy", or "hopeless". Also, Ben-David \& Nel (2013) concluded in a similar research study that utilised SEM: compared with their counterparts, children with disabilities faced more and complicated challenges that inhibited access to adequate resources.

Low self-esteem and feelings of unworthiness were among the factors that determined non-disclosure in a study that was carried on a sample of 67 CSA adult survivors. According to these survivors, other personal barriers (such as internalised survivor blaming, mechanisms to protect self, immaturity) at the time of abuse were also part of the factors that inhibited CSAD (Collin-Vézina et al., 2015). Lack of social status based on gender or age in the community makes the survivors assume they would not receive any support after disclosure. If the survivor relies on the perpetrator for economic support, disclosure may be rare. In societies where women are valued as less than their male counterparts, female survivors may feel intimidated to disclose. Other research indicates the age of the survivor determines disclosure (Easton, 2013).

\section{METHODOLOGY}

Case study research design was employed for its ability to explore more than one source of information and derive multiple themes (Davis et al., 2013). The case study is a research method widely used in social science that includes in-depth interviews since it is shown to provide more realistic responses than purely statistical surveys. A case study tries to deliberately isolate "a small study group or even one individual case" (Guetterman and Fetters, 2018). The use of case study research design enabled the researcher to adequately gather stories and experiences of CSA survivors. In this exploratory process, the researcher was keen to document feelings, beliefs, values, and attitudes expressed by participants as persuaders or inhibitors to disclosure.

Quantitative data was achieved using questionnaires and interview schedules and variables such as child's gender, sex, education, etc., were easily identified and categorised.
Purposive sampling was applied to select TL5H in Kiambu County because it is the only Clinical Management and Referral Centre for Child Sexual Abuse Survivors in Kiambu County. The selection of child study participants was made through purposive sampling from the pool of CSA survivors. This was guided by the state of receiving both medical treatment and therapeutic counselling at the hospital during the period of the current study. Participants (CSA survivors) were also purposively selected using the help of a gatekeeper defined in the proposed study as the medical professional who acted as the primary service provider for the survivors. The choice of case study research design utilised in this study recommended the use of gatekeepers to assist the investigator to build a good rapport with the participants (Kennedy-Macfoy, 2013).

Overall, the collection of both quantitative and qualitative data averaged between 2 to 3 hours per child participant. Some of the interviews were also completed later if the child required more sophisticated resources. All processes of sampling were approved by the hospital management as well as the child's parent.

\section{Sample Size Determination}

Smaller sample sizes are recommended for qualitative research. However, the size of the sample should be large enough to achieve adequate data that satisfactorily meets the objectives of the study and also answers the research questions. When determining the sample size, the researcher's goal is to realise a saturation point. A saturation point is achieved when no new perspectives or information is gained after adding more participants to a qualitative sample (Glaser \& Strauss, 1967).

For a phenomenological study like the current one, a sample size of 5-25 is recommended (Creswell, 1998), while other sources recommend at least 6 participants (Morse, 1994). Thus, the study used a sample size of 40 survivors. In addition to these recommendations, the sensitive nature of the study mandated that the researcher keep a small size of participants in order to ensure their emotional and physical needs were met based on the accessible resources and personnel at Thika Level Five Hospital. 


\section{RESULTS}

This section presents findings from CSA survivors who participated in the current study. However, because survivors were minors, the researcher captured responses from both children and caregivers to gather the survivor's perspective and their experiences surrounding CSA and CSAD. Each survivor, accompanied by at least one caregiver, completed a Sexual Abuse Disclosure
(CSAD) process at Thika Level 5 Hospital as part of the qualifying criteria. Survivors' age was divided into three main categories, ranging between 5 to 17 years, based on the Kenyan law interpretation of who can be termed as a child. The findings presented in Table 1 pertain to the survivors' CSA demographic characteristics; These include age, gender, education level, and health of the child.

Table 1: CSA survivor's Socio-Demographic Characteristics

\begin{tabular}{llll}
\hline Variable of Participant $(\mathbf{n = 3 0})$ & Categories & Frequency $(\mathbf{n})$ & Percentage $(\%)$ \\
\hline Age & 4-8 years & 8 & 26.6 \\
& $9-13$ years & 15 & 50.0 \\
& $14-<18$ years & 7 & 23.4 \\
\hline Gender & Male & 5 & 16.7 \\
& Female & 25 & 83.3 \\
\hline Education level & High & 8 & 26.7 \\
& Low & 21 & 70.0 \\
& None & 1 & 3.3 \\
\hline Health of the child & Good & 28 & 93.3 \\
& Poor & 2 & 6.7 \\
\hline
\end{tabular}

\section{Survivor's Age on CSAD}

The ages of survivors who participated in this study were recorded in order to ascertain the age distribution of the children who were involved. The results (Table 1) indicated that most of the CSA survivors involved in the disclosure process were between 9 and 13 years, representing 50\% $(n=15)$ of the total number of survivors in the study. Those 4 to 8 years represented $26.6 \% \quad(n=8)$, whereas between 14 and 17 years represented the lowest percentage of $3.4 \%(n=7)$.

\section{Survivor's Gender}

CSA survivors' gender was recorded to determine the gender distribution of the participating survivors
(Table 1). Two general categories of gender (i.e., male and female) were used in separating the gender of the children who had experienced abuse. Results indicated that $83 \%$ of the survivors in the study were female. Figure 1 demonstrates how TL5H counsellors keep a monthly tally of the sexual survivors who check-in at the hospital. This independent tally and not related to the current study was recorded between January and June (year), which indicated more girls than boys participated in the CSA counselling and treatment program at TL5H Clinical Management and Referral Centre for CSA. The tally was posted on the wall in the counselling room where the researcher conducted the interviews. 
Figure 1: Sample of Survivor's Monthly Tally, by Gender, at TL5

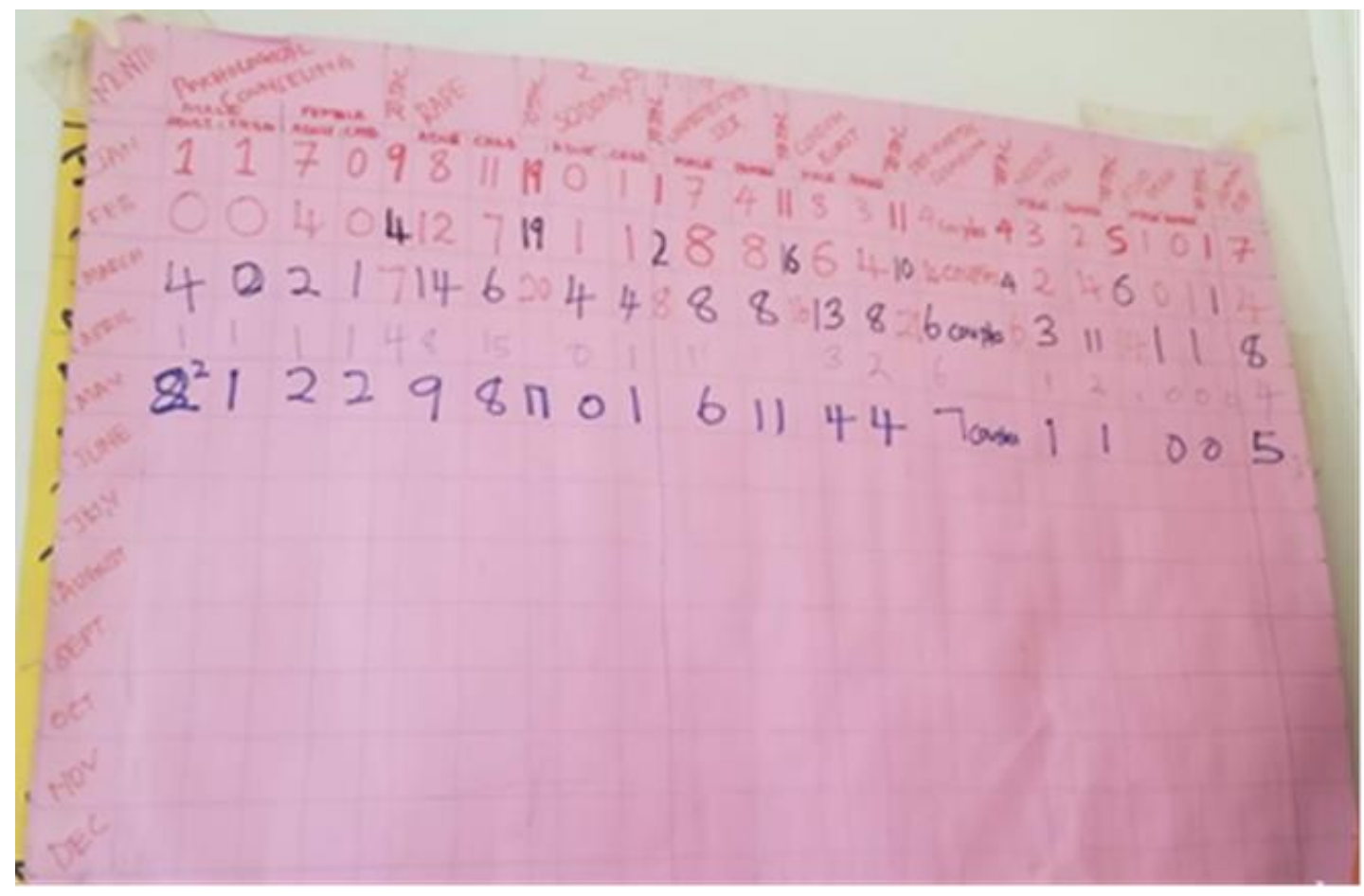

\section{Survivor's Level of Education}

The level of education of the child participants was also recorded and grouped into three main categories, i.e., High (attended high school), Low (attended primary school), and none (no school attended). The questionnaires were filled according to the level of education the survivor had achieved by the time CSA occurred. The percentages and frequencies were used in the analysis of the results presented in Table 1. Results illustrated that most of the survivors that disclosed abuse had at least achieved a lower level of education, comprising $70 \%(\mathrm{n}=21)$ of the total number of survivors in this study. Those that had achieved a higher level of education who were abused represented $26.7 \%$ $(n=8)$ of the child participants, whereas those who had no formal education stood at $3.3 \%(n=1)$.

\section{Survivor's Health}

The health status of the survivors was also an important criterion to qualify the child participant since this study was carried out in a hospital setting to ensure that the survivors were only at the clinic due to a CSA incident. Survivors' health was captured in the doctor's records around the time
CSA and disclosure were occurring, between April and September of 2019. Two general categories were used to indicate the health of the child, i.e., good and poor. Good health meant that the child was not suffering from any known illness, whereas poor meant that the child had some form of illness or a known health condition. From the findings (Table 1), $93.3 \%$ of the survivors were deemed to be in good health before abuse, whereas those who suffered from poor health before abuse constituted $6.7 \%$.

\section{Survivor's Disability}

The disability status of the survivors in this study, as reported by the caregivers, helped to establish if it interfered with the child's ability to disclose. Two main categories, as observed in survivors and gathered from caregivers' narratives, were used to represent the physical and mental status of the survivor, i.e., "Normal" meant the child had no physical or mental disabilities depending on the doctor's perspective. Results are presented in Table 1 , whereby $83.3 \%(\mathrm{n}=25)$ of the survivors were considered normal as compared to $16.7 \%(\mathrm{n}=5)$ who reported some form of physical or mental 
disability (e.g., learning disability, autism, attention deficit, hyperactivity, etc.).

Figure 2: Figure 2: Survivor's Drawing 1

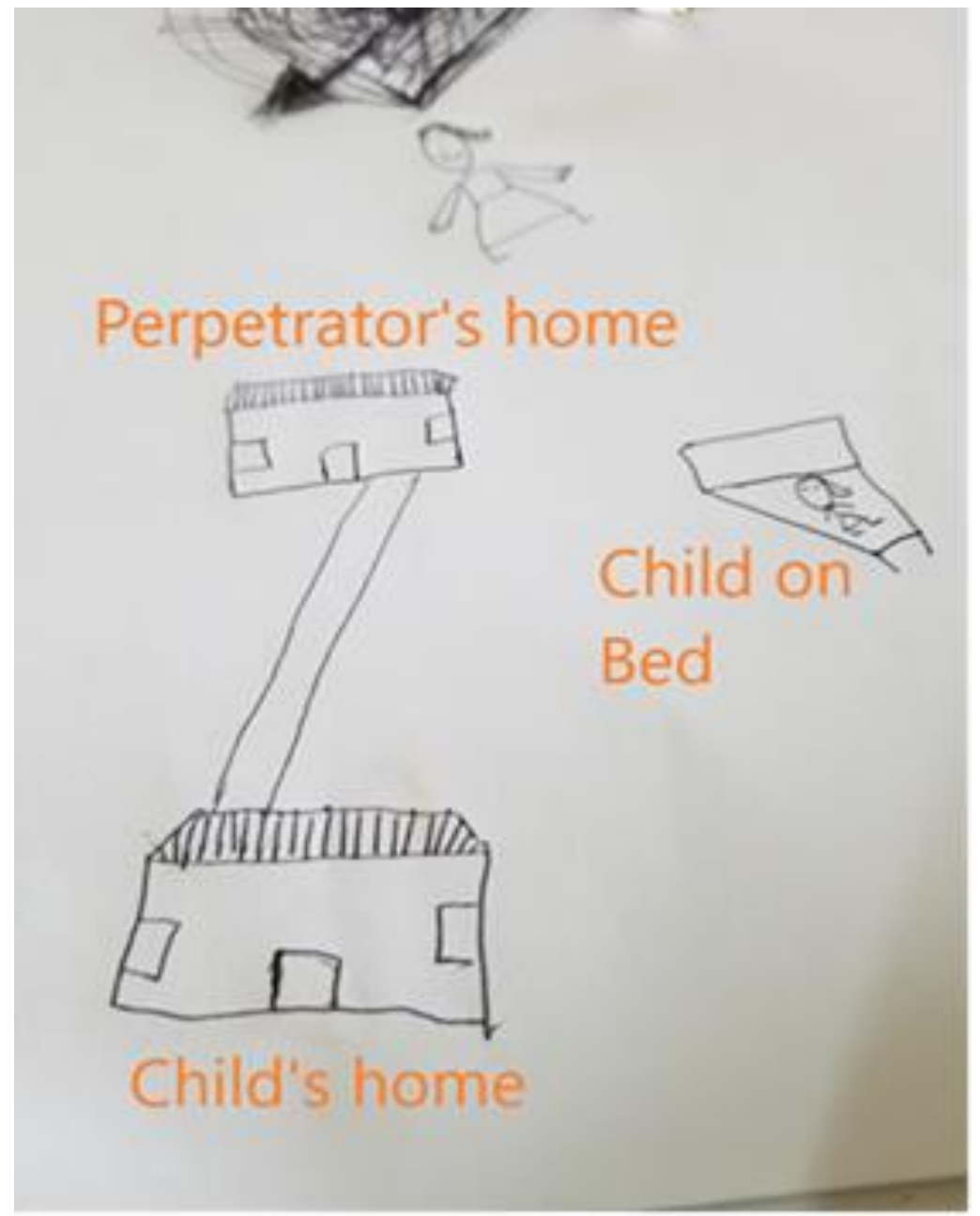

Note: Child 3 drew this picture to illustrate her incident that turned into both her neighbourhood map and a house layout. She also used the drawing (Figure 2) to illustrate the bed where the rape happened. Survivors' ability to describe an abuse was greatly influenced by their ability to speak, write, draw, or remember the abuse accurately. Children's behaviour, caregivers' responses, and doctor's records were also collaborated by the researcher's observation during the current study.

\section{Survivor's Emotions after Abuse}

The study sought to establish some of the emotions that the survivors felt or expressed immediately after the abuse occurred. In an attempt to capture some of the physiological effects that survivors were experiencing as a result of CSA, the researcher asked questions such as, "tell me things that make you happy or tell me things that make you unhappy". Survivors' feelings were categorised as fear, shame, anger, and not understanding; and were later subjected to descriptive statistics in the form of frequencies and percentages as shown in Table 1 above.

When the survivors were asked to name their emotions that occurred after abuse, 46.7\% ( $n=14)$ experienced fear; $23.3 \%(n=7)$ experienced shame; $13.3 \%(n=4)$ experienced anger; while $16.7 \%(n=5)$ were unable to express their emotions. Both survivors and caregivers' responses consistently 
indicated fear as the most common feeling. This feeling led to neither the child nor the family knowing what to do, what would happen if abuse was reported, and what would happen if others knew about it. Further, as most survivors expressed during the interview, when the researcher asked a 12-year-old female survivor this standard question, "how come you did not want anybody to know what had happened", the child gave the following response:

"I was afraid my mother would leave my father...." (Child 10) On the other hand, when another survivor was asked why she reported her abuse, she explained that she was afraid her mother would be mad if she found out the pregnancy was as a result of abuse: "I feared I would become pregnant ..." (child 12)

Other survivors perceived the abuse as either an embarrassment to their families or to them, while others expressed anger and resentment toward the perpetrator. Some of these feelings dictated the steps that the survivors took a right after the abuse:

"I was embarrassed to talk about it...so I stayed in bed without telling anybody" (Child 9).

"I never wanted others to know .... I didn't want people to think I am a bad child ...." (Child 9)

"I was angry at my uncle for doing bad things to me...so I needed to tell my mother as soon as it happened..." (Child 13)

"I don't know how to feel.... I am only here because my parents told the police about it..." (Child 10).

\section{DISCUSSION}

The study considered age, gender, education level, health, religion, etc. as some of the characteristics that defined a survivor in the ecological model. Based on the quantitative data, survivors below 8 years represented $26.6 \%$, whereas between 14 and 16 years represented $23.4 \%$ of the child participants. Survivors between the age of 9 to 13 years were more likely to disclose sexual abuse when compared with the other age groups in the study. Based on the data from the current study, most of the CSA survivors involved in the disclosure process were between 9 and 13 years, representing $50 \%$ of the total number of survivors at TL5H. Since age was a criterion for the child participants, younger than 5 years were excluded because they lacked communication and comprehension skills to narrate their CSA abuse experiences.

Consistent with the findings, past research that examined predictors of CSAD from the offender's perspective published that disclosure was positively related to survivor's age (Leclerc \& Wortley, 2015). In the current study, survivors in the mid-age group were found to be more expressive than the other groups. Overall, the current study established through interviewing the medical and social providers that compared to the younger survivors, the older children were more embarrassed about sexual abuse making it more difficult to disclose or sick treatment at TL5H, which is consistent with the literature (Easton, 2013). Also, in support of the medical providers' claims and researcher's observation, a Tanzania study by Kisanga et al. (2011) associated delayed or no disclosure with stigma and shame. Since the older survivors at TL5H regarded CSA as shameful, this could have also resulted in their failure to disclose CSA to caregivers which coincides with the low attendance rate of their age category at TL5H.

There were two general categories of gender (i.e., male and female) used to separate the survivors in the study. Based on the results, $83 \%$ of the survivors were female, making gender an important aspect in disclosing child sexual abuse. This observation was also consistent with TL5H medical providers' anticipation of a higher percentage of female survivors during data collection. The trend of higher CSA reports at TL5H in female survivors, compared to their male counterparts, matches the global CSA literature (Meinck et al., 2017; Pereda et al., 2009; Schonbucher et al., 2012; UNICEF, 2014).

Although the current study reported higher CSAD for females, it is not clear whether being female contributed to CSAD at TL5H, but it was established that effects of CSA, such as pregnancy and STDs, and other complications led the caregivers to bring their kids to TL5H, which eventually ended in disclosure. For example, a caregiver explained she brought the daughter to the 
hospital because she was afraid the perpetrator had impregnated her.

Other studies had suggested a global prevalence of Child Sexual Abuse in high school girls (Pereda et al., 2009; Wihbey, 2011). As much as girls are more likely to be abused, a similar study on male survivors (Easton, 2013) discovered that additional gender aspects (e.g., masculinity, stigma, etc.) prevented male survivors from disclosing CSA. Past literature on CSA (Easton, 2013; Roberts, 2010) supports the current findings of a higher disclosure rate amongst female survivors at TL5H.

The current results illustrated that $70 \%$ of the survivors that disclosed abuse had achieved a lower level of education. Survivors who had achieved a higher level of education represented $26.7 \%$ of the child participants and those who had no formal education stood at $3.3 \%$. The medical providers at TL5H had predicted this trend at the initial meeting, claiming that younger and non-school-aged children around the slums of Thika become targeted by perpetrators because they are unsupervised or "home alone" whenever their caregivers go to hassle in Thika City. Additionally, some of the survivors' siblings participated in long school hours. One guardian narrated how she left home before dawn and returned "very late at night" after she closed her market.

Survivors' cognitive and communication skills, which were related to their education level, either enhanced or barred the survivors' ability to disclose and express themselves regarding CSA events. In the current study, those are the same survivors that were excluded from the study and left only one child with no formal education, which is in line with other past CSA research findings (Jackson et al., 2015) established that most of the CSA survivors' feelings of powerlessness prohibited disclosure.

This study indicated at least $93.3 \%$ of the survivors were deemed to be in good health before abuse, whereas those who suffered poor health before abuse constituted $6.7 \%$. Health was an additional child characteristic that was reported by caregivers as important, which also helped the researcher to ensure that the child was only at TL5H for CSArelated issues.
Some of the medical providers made remarks search as "perpetrators know healthy kids", meaning that the child's health may have played a role to make the child a CSA target. This claim was later confirmed by caregivers' confessions of how their children were rarely sick until the abuse happened:

"My child was spending too much time in the toilet and I had to check on her...I noticed that my son was acting sick and in pain... when I went to check on him, he was groaning in pain...this made me interrogate him that led to disclosure...."

The mental health of the child was also an important factor in the disclosure process since children who were said to be too traumatised to communicate; these children were eliminated from the current study to prevent secondary trauma. Hence, TL5H Clinical Management and Referral Center was set up to provide counselling therapy as the first treatment plan to the survivors before the interrogation process. Any other survivors (such as Child 16 in the current study) with major physical injuries related to CSA received treatment before interviews began to eliminate barriers to disclosure at TL5H. Children who attended the clinic with other non-CSA health issues did not participate in the study. During the research, the researcher was forced to stop any interviewing for survivors who expressed distress and trauma. Overall, good mental and physical health were found to be vital for survivors, necessitating therapy before and after disclosure at TL5H, which was consistent with previous research (Easton, 2013).

Like the child's health, disability was another important child factor regarding disclosure. With $83 \%$ of the survivors categorised as normal, this was an important aspect that enhanced the disclosure. The children in the study had no limitations in expressing their experiences and telling their stories. Even though there is a lack of evidence in how disabilities impact disclosure, the findings from this research determined that disclosure and treatment processes were uninterrupted if the child's ability to move around the space at TL5H was not limited. In the initial stages, the researcher eliminated children who had severe disabilities that prevented them from providing assent, expressing themselves, or either because their hearing or eyesight was limited. In addition, a child that had a 
severe mental disability would not have participated in the study because of its complicated confidentiality issues.

Finally, survivors' at TL5H said that how they felt after the abuse played an important role in their disclosure process. Survivors expressed having reported the abuse because they were angry or refused to disclose because they were felt shame, fear, or anger. These findings are supported by past research studies (Easton 2013; Jackson et al., 2015; Karakurt \& Silver, 2014). The survivors fear retaliation, breaking families, and losing economic support by the perpetrator.

\section{Limitations}

Some limitations of this study include the sample size. Due to the sensitivity of this study and based on the preliminary survey, the researcher decided on a small sample of thirty survivors making it harder to generalise the results outside Thika county. Limited availability of similar research studies and literature in Kenya and other African countries in the proposed topic may have limited cultural understanding of the issue that was studied. It is because most research on this topic has been carried out in western countries.

Despite the stated limitations, this study brought unique insights from survivors and the stories they gave should be on the issue of Child Sexual Abuse in Thika Level 5 Hospital in Kiambu County and Kenya. It was considered thought-provoking by participants, service providers, and community leaders. Throughout the research period, Child Sexual Abuse remained a very delicate issue to discuss and define amongst the participants and service providers; hence the proposed need to put more emphasis on the survivor's stories rather than the statistical significance of the explored factors.

\section{CONCLUSION}

The study established that the survivor's sociodemographic characteristics were important in determining CSAD at Thika Level 5 Hospital in Kiambu County. Survivors between the age of 9 to 13 years were more likely to disclose sexual abuse when compared with the other age groups in the study. While the study excluded the below 9 years old for less ability to express themselves, the findings imply that the more mature children (past 13 years) had gained some sense of shame that might have kept them away from sharing their sexual abuse stories. Alternatively, the more mature children could be more traumatised than the younger ones through denial of the happening. The study revealed the majority $(83 \%)$ of the survivors were female, making gender an important aspect in disclosing child sexual abuse. This means that the male children could be interpreting the abuse as a normal incident that may not call for reporting or telling. The results also illustrated that majority $(70 \%)$ of the survivors that disclosed abuse had achieved a lower level of education. This is critical with the implication of the more likely shame among the higher education level groups. This study indicated at least $93.3 \%$ of the survivors were deemed to be in good health before the abuse. This may be related to denial as a strange incident, unlike those who had health issues before - they may be interpreting it as just one of the other health issues they have suffered before.

\section{Recommendations}

Children need to be supported from all levels of the ecological systems in order to promote disclosure. Based on the current research findings, as described by the following survivors' statements, the Thika law enforcement unit demonstrated a lack of empathy and resources for the children that were disclosed. Since the study indicated that survivor's socio-demographic characteristics (e.g. gender) were mentioned as important factors to encourage CSAD in Thika Level 5 Hospital in Kiambu; hence, a recommendation is made to the Thika county government to establish and enact policies that provide a safe environment for the Kenyan children, initiate surveillance systems and protective measures to monitor and curb CSA.

This research recommends the following policies to support CSAD in TL5H: Craft new laws and policies that mandate adults in Kenya to report Child Sexual Abuse as soon as it occurs. Strengthen existing laws and policies to support and encourage survivors to report the CSA. All adults should be sensitised to inform children workers and service providers about these policies that safeguard children.

70 | This work is licensed under a Creative Commons Attribution 4.0 International License. 
Create systems and forums that empower children and inform their rights to protection against abuse while parents and adults in their lives are mandated to support the disclosure process after CSA is identified or suspected.

\section{REFERENCES}

Ben-David, B., \& Nel, N. (2013). Applying BronfenBrenner's ecological model to identify the negative influences facing children with physical disabilities in rural areas in Kwa-Zulu Natal. Africa Education Review, 10(3), 410-430.

Cantón-Cortés, D., Cortés, M. R., \& Cantón, J. (2012). The role of traumagenic dynamics on the psychological adjustment of survivors of child sexual abuse. European Journal of Developmental Psychology, 9(6), 665-680.

Collin-Vézina, D., De La Sablonnière-Griffin, M., Palmer, A. M., \& Milne, L. (2015). A preliminary mapping of individual, relational, and social factors that impede disclosure of childhood sexual abuse. Child Abuse \& Neglect, 43, 123-134.

Creswell, J. W. (1998). Qualitative inquiry and research design: Choosing among five traditions. London: Sage Publications.

Davis, D. W., Pressley-McGruder, G., Jones, V. F., Potter, D., Rowland, M., Currie, M., \& Gale, B. (2013): Evaluation of an Innovative Tool for Child Sexual Abuse Education. Journal of Child Sexual Abuse, 22(4), 379-397.

Easton, S. D. (2013). Disclosure of child sexual abuse among adult male survivors. Clinical Social Work Journal, 41(4), 344-355.

Glaser, B. G., \& Strauss, A. L. (1967). The discovery of grounded theory: Strategies for qualitative research. Piscataway, New Jersey: Transaction.

Guetterman, T. C., \& Fetters, M. D. (2018). Two Methodological Approaches to the Integration of Mixed Methods and Case Study Designs: A Systematic Review. American Behavioral Scientist, 62(7), 900-918. https://doi.org/10.1177/0002764218772641
Jackson, S., Newall, E., \& Backett-Milburn, K. (2015). Children's narratives of sexual abuse. Child \& Family Social Work, 20(3), 322332.

Karakurt, G., \& Silver, K. E. (2014). Therapy for childhood sexual abuse survivors using attachment and family systems theory orientations. The American journal of family therapy, 42(1), 79-91.

Kennedy-Macfoy, M. (2013). 'It's important for the students to meet someone like you.'How perceptions of the researcher can affect gaining access, building rapport and securing cooperation in school-based research. International Journal of Social Research Methodology, 16(6), 491-502.

Kisanga, F., Nystrom, L., Hogan, N., \& Emmelin, M. (2011). Child sexual abuse: community concerns in urban Tanzania. Journal of child sexual abuse, 20(2), 196-217.

Leclerc, B., \& Wortley, R. (2015). Predictors of victim disclosure in child sexual abuse: Additional evidence from a sample of incarcerated adult sex offenders. Child abuse \& neglect, 43, 104-111.

Meinck, F., Cluver, L., Loening-Voysey, H., Bray, R., Doubt, J., Casale, M., \& Sherr, L. (2017). Disclosure of physical, emotional and sexual child abuse, help-seeking and access to abuse response services in two South African Provinces. Psychology, health \& medicine, 22(sup1), 94-106.

Morse, J. M. (1994). Designing funded qualitative research.

Roberts, S. T., Watlington, C. G., Nett, S. D., \& Batten, S. V. (2010). Sexual trauma disclosure in clinical settings: Addressing diversity. Journal of Trauma \& Dissociation, 11(2), 244-259.

Spröber, N., Schneider, T., Rassenhofer, M., Seitz, A., Liebhardt, H., König, L., \& Fegert, J. M. (2014). Child sexual abuse in religiously affiliated and secular institutions: A retrospective descriptive analysis of data provided by victims in a government-sponsored 
reappraisal program in Germany. BMC public health, 14(1), 1-12.

Schönbucher, V., Maier, T., Mohler-Kuo, M., Schnyder, U., \& Landolt, M. A. (2012). Disclosure of child sexual abuse by adolescents: A qualitative in-depth study. Journal of Interpersonal Violence, 27(17), 3486-3513.

Sumner, S. A., Mercy, J. A., Saul, J., Motsa-Nzuza, N., Kwesigabo, G., Buluma, R., ... \& Hillis, S. D. (2015). Prevalence of sexual violence against children and use of social services-seven countries, 2007-2013. MMWR. Morbidity and mortality weekly report, 64(21), 565.

Townsend, C. (2016). Child sexual abuse disclosure: What practitioners need to know. Available at Darkness to Light: www. $D, 21$.

Ulibarri, M. D., Ulloa, E. C., \& Salazar, M. (2015). Associations between mental health, substance use, and sexual abuse experiences among Latinas. Journal of Child Sexual Abuse, 24(1), 35-54.

UNICEF Data: Monitoring the Situation of Children and Women, 2014. UNICEF Data

Vizard, E. (2013). Practitioner Review: The victims and juvenile perpetrators of child sexual abuseassessment and intervention. Journal of child psychology and psychiatry, 54(5), 503-515.

Pereda, N., Guilera, G., Forns, M., \& GómezBenito, J. (2009). The prevalence of child sexual abuse in community and student samples: A meta- analysis. Clinical psychology review, 29( 4), 328-338.

Wihbey, J. (2011). Global prevalence of child sexual abuse. Journalist Resource. [Last on Aug and Updated on 2011 Nov 15]. Available from: Journalistsresource. org/studies/./global- preva lence-child-sexual-abuse.

World Health Organization. (2003). Guidelines for Medico-Legal Care for Victims of Sexual Violence. Geneva: WHO. Retrieved on $3^{\text {rd }}$ May, 2017 from: http://apps.who.int/iris/bitstream/10 665/42788/1/924154628X.pdf

72 This work is licensed under a Creative Commons Attribution 4.0 International License. 